\title{
TERRA DE NEGÓCIO VERSUS TERRA DE TRABALHO: A TERRA COMO UM DIREITO PARA ALÉM DO APARATO LEGAL
}

\author{
Alceu Zoia ${ }^{1}$ \\ Odimar João Peripolli ${ }^{2}$ \\ Universidade do Estado de Mato Grosso - UNEMAT
}

\section{RESUMO}

O desenvolvimento capitalista transformou a terra em propriedade privada, com direitos absolutos dos proprietários sobre ela. Inclusive o direito de não produzir - reserva de valor (terra de negócio). A atual legislação, ao tratar da função social da terra, tenta romper com o conceito de propriedade como um direito sagrado e inviolável, o que tem possibilitado que muitas "cercas" fossem erguidas, impedindo o acesso e/ou a expropriação de muitos trabalhadores. Neste trabalho nos propomos trazer para a reflexão à questão da propriedade da terra enquanto um direito para além do aparato legal. $\mathrm{O}$ acesso à terra tem se colocado como condição indispensável para os que buscam se reproduzirem enquanto camponeses. Estamos falando de um bem voltado à produção de toda forma de vida, de outras vivências e convivências (terra de trabalho) para além daquelas impostas pelo projeto do capital. Ou seja, o direito à terra como um direito humano.

Palavras- chave: Terra; Trabalho; Camponês.

\section{BUSSINES LAND VERSUS WORK LAND: THE EARTH AS RIGHT BEYOND THE LEGAL APPARATUS}

\begin{abstract}
The capitalist development transformed the land into private property, with absolute rights of the owners about it. Including the right not to produce - a store of value (land business). The current legislation, when deal with the social function of land, tries to break away from the concept of property as a sacred and inviolable right, which allowed that many "fences" were erected, precluding access and / or expropriation of many workers . In this paper we propose to think the question of land ownership as a right beyond the legal apparatus. Access to land has been set as a indispensable for those who seek to reproduce while peasants. We are talking about a property focused on the production of all forms of life, from others experiences and cohabitation (working land) beyond those imposed by the capital project. In other words, the right to land as a human right.
\end{abstract}

Keywords: Land; Work; Peasants.

\section{Introdução}

É verdade que depois de derrubadas as cercas do latifúndio, outras cercas se levantarão: as cercas do judiciário, as cercas da polícia (ou das milícias privadas), as cercas dos meios de comunicação de massa... Mas é verdade também que cada vez mais caem cercas e a sociedade é obrigada a olhar e discutir o tamanho das desigualdades, o tamanho da opulência e da miséria, o tamanho da fartura e da fome.

(Pedro Tierra) $)^{3}$ 
A história das civilizações nos mostra que as mais diferentes sociedades humanas, em todos os períodos e formas de organização, sempre deram especial atenção a terra. Este cuidado esteve voltado tanto à questão do uso quanto o da ocupação. Acreditase que tal comportamento justifica-se a considerar que era dela, única e exclusivamente, que dependia o sustento das populações. Ou, a sobrevivência destes dependia da forma como estes a tratavam. Longe das tecnologias e inovações produzidas pela ciência que exercem grande importância sobre a produção, o cuidado e zelo para com a terra, era uma condição sine qua non para que pudessem continuar existindo. A terra provia, mas, era preciso cuidá-la. Não havia outra saída.

Neste contexto adverso, ausente de possibilidades de recursos, os povos se organizavam conforme as possibilidades dadas pela terra. Em outras palavras, de acordo com as condições dadas pela terra ${ }^{4}$. O que implica em dizer que vivências e convivências foram sendo definidas e se constituíram no tempo de acordo com os fenômenos naturais mais adversos: o dos ventos gelados dos polos, até o calor sufocante das regiões tropicais.

Como reconhecimento às muitas possibilidades que esta lhes possibilitava, os povos foram aprendendo a respeitá-la, a amá-la de uma forma tal que aqueles sentimentos que se parecem com o do filho/a para com o pai/mãe, fossem transferidos à terra. Tanto que passaram a chamá-la, como é o caso dos povos originários da América Latina, de mãe, a Pacha Mama (MARÉS, 2003) 5 .

Esse sentimento é assim descrito por Oliveira (2010):

A terra no mundo ameríndio é elemento comum e central em todas as culturas latino-americanas. Para incas, maias, astecas, guaranis e todas as outras culturas originárias da América a terra é o lugar sagrado, lugar de encontro com Deus. A terra mãe dá bons frutos, é o lugar onde descansam os antepassados, é a raiz da economia do povo, de sua cultura e espiritualidade. A Pachamama andina não é um simples meio de produção, mas algo sagrado, centro da vida comunitária. Um índio sem terra é um índio morto. É parte do corpo pessoal e social do povo. Entre os aimaras a Pachamama ou Wirjina (virgem) também merece respeito. Oferecem-lhe libações pela colheita e partilha dos frutos. Família, terra e animais estão ligados. Há relação entre os frutos da terra e o comportamento das famílias. A terra é objeto de contemplação. No mundo guarani a terra é principalmente a floresta, que inclui animais, rios, lagos, etc. é o substrato donde brota a selva. É um corpo vivo (tekohá). Mas ela também está cheia de males, que é o rompimento desta harmonia, por parte dos seres humanos. Ganha importância aí o mito utópico da busca da terra sem males.

Estas considerações sinalizam o objetivo ao qual nos propomos neste artigo, qual seja, trazer para a reflexão o tema voltado à terra: a terra como um direito. Porém, o direito visto para além da perspectiva da lei: que extrapola e/ou se limita à legislação que o constitui. $\mathrm{O}$ direito à propriedade da terra, garantido pela legislação, garante a propriedade da terra a alguém. Lhes garante porque está "nos conformes da lei" (coisa legal). O legal, todavia, não garante que esta exerça sua função social, e/ou mesmo garante o direito à vida. Como diz Marés (2003, p. 13), "a propriedade da terra gera males paradoxais porque destrói a natureza com força devastadora e argumenta que mais precisa destruir para dar de comer a desesperado e incontável contingente humano". Por irônico que possa parecer, e de fato o é, ressalta, "quanto mais destrói a natureza, menos vida possibilita, inclusive 
humana, quanto mais altera os seres vivos, mais se aproxima da morte" (Ibid. p. 13). E conclui: "há algo de errado nessa lógica inversa, não é possível que a garantia de um direito individual seja o flagelo do direito dos povos à vida" (Ibid. p. 13).

Por que questionarmos o legal, o estabelecido em lei, se lei é lei e deve ser cumprida? Como diziam os romanos: "dura lex, sed lex" (a lei [é] dura, mas [é] a lei). Ora, se o que está escrito é resultado da produção humana, esta pode ser questionada. Ou seja, se construída, pode ser desconstruída. As leis, via de regra, são resultado de embates, disputas, relação de força entre classes com interesses antagônicos. Sobretudo, interesses políticos e econômicos.

A lei cabe garantir a todos, indistintamente, que os direitos contidos na Constituição, sejam estendidos a todos: "Todos são iguais perante a lei" (art. 5\% CF/88). Ao garantir direitos individuais, não significa fazê-lo de forma que estes venham de encontro e/ou que venham em prejuízo do coletivo. O bem comum está cima de qualquer prerrogativa individual. Em outros termos, que venha ao encontro dos interesses coletivos como a erradicação das desigualdades sociais, da pobreza, a promoção da solidariedade e dignidade da pessoa.

$\mathrm{O}$ artigo $5^{\circ}(\mathrm{CF} / 88)$ reza que (inciso XXII): "é garantido o direito de propriedade". Um passo adiante (inciso XXIII), ao que parece, vem complementá-lo: "a propriedade atenderá a sua função social". É garantido (direito de propriedade), desde que esta cumpra sua função social. Como esse direito não é estendido a todos que dela precisam, ou os que o tem não a colocam para o bem comum, servir aos outros, esse se torna um direito excludente, acumulativo, individual, absoluto. Exclui-se o coletivo. E olha que esse direito é "considerado a essência do processo civilizatório (MARÉS, 2003, p. 12). Contraditório, portanto, pois traz, dado sua natureza (individualismo, egoísmo), o germe da destruição: observe-se a natureza (florestas, rios, solo), as pessoas/sujeitos (violência, morte), o descaso para tudo o que se refere aos outros/coletivo.

Não há como negar o discurso ideológico presente na lei. Quem a cria e quem a interpreta tem mais poder de quem simplesmente a obedece, a classe trabalhadora; para a elite dominante, que a dita e a interpreta, há sempre outras possibilidades de interpretações: aquelas que vão além do que está escrito. O que nos leva concluir que, na prática, nem todos são iguais perante a lei, como reza a lei.

Há que se levar em consideração estes aspectos quando nas discussões sobre as muitas questões agrárias estão envolvidas, como é ocaso da propriedade da terra enquanto direito para além do aparato legal. Entre o legal e o justo poderá haver (ou há) uma distância muito grande. Partindo do entendimento de que a realidade se constrói na relação, na luta e na disputa pelo poder - sem que leve em consideração os diferentes aspectos que envolvem as questões do campo, corre-se o risco de ficarmos no discurso fácil.

Zibetti (2005, p. 14) chama a atenção para o fato de que a terra não tem apenas função econômica - valor da alimentação e bens advindos da atividade rural. Ela tem também uma dimensão social - subsistência e empregabilidade como direitos humanos de toda coletividade, bem como a função ecológica - sustentabilidade da terra. Para o autor, a terra, considerando-se atmosfera, solo, água e biota (conjunto de seres vivos de um ecossistema), além dos movimentos que executa, "é um verdadeiro ser vivo" (Ibid., p. 15).

Acreditamos que nossas discussões, tendo em vista a temática, ganham maior sentido na medida em que caminham para o entendimento de que a terra vista e buscada se torna um bem coletivo, quando desempenha, de fato, sua função social. $O$ direito "sagrado" da terra deve constituir-se em um direito coletivo. Aqui está o verdadeiro sentido de Pacha Mama (terra mãe). 


\title{
A propriedade da terra: critérios de distribuição
}

No princípio dos tempos a terra não tinha dono. Questiona-se, portanto, quem e sob que critérios foi delegado (dado a missão) de distribuí-la? Quem e sob que critérios alguém tinha o direito de ser dono de uma pedaço de terra? "É muito recente e localizada a prática de concentrar a produção num espaço de terra, e ainda mais recente transformar essa concentração em proveito de uma única pessoa e chamar isso direito de propriedade" (MARÈS, 2003, p. 12).

As muitas considerações vão, aos poucos, nos levando ao entendimento do que comumente chamamos de processo. Vamo-nos dando conta do que houve com a terra (a partir da apropriação e uso) quanto à concepção e práticas de valores e princípios que, voltados ao coletivo, paulatinamente, foram sendo levados à prática de uma ruptura, pondo fim à harmonia entre homem e natureza. Essa harmonia, ao que nos parece, estaria/está relacionada ao comunismo primitivo ${ }^{6}$.

Diz-se, portanto, que do que era voltado à prática e cultivo dos valores e princípios voltados ao atendimento dos interesses coletivos, volta-se para os interesses privados.

\begin{abstract}
A agricultura fez da terra um espaço privado, os homens, ou melhor, cada homem passou a controlar o seu produto e a partir daí se promoveu uma mudança de comportamento ético, passando o ser humano a se considerar o destinatário do Universo, subjugando todos os animais e plantas e, ao final, a supremacia de alguns homens sobre todos os outros homens. $\mathrm{O}$ ser humano perdera o paraíso, no mito da criação (MARÈS, 2003, p. 12).
\end{abstract}

Este caminho de ruptura não ocorre de uma hora para a outra ou de forma espontânea. Muito menos de forma abrupta. Pelo contrário, estamos falando de construção histórica. O que, por sua vez, implica afirmar que não se trata de algo linear, harmonioso, sem conflitos. Em outros termos: obedece a um processo de produção humano, histórico. Portanto, intencional, com interferência humana, num jogo que se faz atravessado por diferentes interesses, os de classes. Obedece ao que Marx e Engels (2002, p. 40) chamam de luta de classes: "a história de todas as sociedades até hoje existentes é a história das lutas de classe".

O primeiro passo quanto ao rompimento desta "harmonia" no campo/terra começa com a descoberta da agricultura. Esta prática de cultivar a terra transformou-a - de propriedade coletiva, de muitos "donos" - em propriedade privada - de um, ou poucos donos. Com a agricultura, cada família/grupo passou a cuidar melhor da "sua" produção, da "sua" propriedade, do "seu" cultivo, da "sua" porção/lote de terra. O "nosso" é substituído pelo "meu".

Como pano de fundo desta questão, o que se percebe, é que na base de tudo - o início das desigualdades - está a propriedade privada da terra. A partir de então, "a propriedade ganha o status de direito absoluto, sagrado e inviolável" (ZIBETTI, 2005, p. $87)^{7}$. Ao se referirem à propriedade privada (inclusa a da terra), importa mencionarmos as palavras de Marx e Engels (2002, p. 52) quando afirmam ser esta a protagonista de todos os males na sociedade: "Mas a moderna propriedade privada burguesa é a última e mais perfeita expressão do modo de produção e de apropriação baseado nos antagonismos de classe, na exploração de uns pelos outros".

Materializa-se desta forma o mito utópico da busca da terra sem males; a perda do paraíso, o mito da criação: 
A terra é dom de Deus, não apenas algo material. É herança (Dt 12,10); as suas primícias são oferecidas a Deus $($ Ex 23,14$)$. Não pode ser vendida ou alienada, o povo não é proprietário, mas arrendatário ( $\operatorname{Lv} 25,23)$. A terra requer trabalho. Terra é comunitária. Durante o exílio, a tradição sacerdotal formulou alguns comportamentos e regras sobre a terra. Como filho de Deus, criado da terra, todo ser humano tem direito à terra, de trabalhar e de não ser escravo (OLIVEIRA, 2010).

Mas,

A terra é profanada e se torna maldita (Gn 3), quando a terra se converte em objeto de exploração e lucro. No tempo da monarquia isso fica claro (1Sm 22,7 e 1Rs 21, 1-9). Empobrecimento de uns e enriquecimento dos outros. Os profetas denunciam esta realidade de opressão: Amós, trabalhador rural denuncia o luxo dos comerciantes e ricos frente à pobreza do povo desterrado; Oséias recorda que a terra é de Deus e não de Baal; Isaías diz que as vinhas de Israel estão produzindo frutos de injustiça e diz que Deus está ouvindo clamor de seu povo; Miquéias se lamenta dos que cobiçam campos e os roubam do povo; os autores do Deuteronômio exortam à mudança recordando o amor de Deus que cuida da terra e dá abundantes colheitas; Jeremias é o profeta da terra (a profanação da aliança é a profanação da terra) (Id.).

Paulatinamente, a terra - propriedade coletiva - seus frutos (produção) passou a ter "um" dono (propriedade privada). Isto é, propriedade e produção passam a se constituir como um direito, agora, garantido por uma lei. Um direito pleno, sem limites e que, como ressalta Marés (2003), levou os proprietários a usufruí-lo da forma que lhes convinha, inclusive o direito de não fazê-la produzir.

Aqui está a origem das muitas questões relacionas à terra, ou seja, as questões agrárias em nosso país. Sendo uma propriedade privada, onde estaria/está o mal em usá-la da forma que os proprietários lhes aprouverem? A princípio, nenhum. Ocorre que esse direito, levado às últimas consequências, implica, como regra, "tirar" do outro outros direitos, negando-lhes a possibilidade de uma vida digna: terra, trabalho, alimento, moradia, educação/escola, lazer. A uns poucos, muito; a muitos, pouco ou nada. Aqui está a origem das desigualdades ${ }^{8}$.

Portanto, a ideia da propriedade privada da terra, como um direito individual, absoluto, pleno, é uma construção do homem. É algo construído, pensado, resultado de um conjunto de fatores atravessados pela disputa, jogo de interesses, de luta, de poder, características intrínsecas ao sistema capitalista formado por classes sociais.

A sociedade burguesa moderna, que brotou das ruínas da sociedade feudal, não aboliu os antagonismos de classe. Não fez mais do que estabelecer novas classes, novas condições de opressão, novas formas de luta em lugar das que existiram no passado (MARX e ENGELS, 2002, p. 40).

Basta olharmos à nossa volta (tomemos como exemplo a região Amazônica do norte do Estado de Mato Grosso, campo empírico de nossas pesquisas) ${ }^{9}$. O modelo de agricultura e pecuária implantado pelo agronegócio (latifúndio-monocultor-exportador). Extremamente rentável para o modelo capitalista, onde a ideia do lucro está à frente de qualquer atividade, em detrimento de um projeto que se busca sustentável para atender os interesses e necessidades que sejam de um coletivo maior, como garantia de um futuro 
próximo possível para a sobrevivência de todas as formas de vidas necessárias ao equilíbrio do planeta terra.

Há que se questionar o entendimento da propriedade privada da terra sendo a "essência do processo civilizatório" (MARÈS, 2003). Esse projeto do capital nos coloca diante de uma realidade extremamente contraditória: poucos ricos versus muitos pobres; destruição da natureza; expropriação/exploração da massa trabalhadora do campo; perda da terra; miséria; favelização do campo ${ }^{10}$; conflitos agrários; mortes no campo. Neste cenário, há que se questionar: como definir a propriedade privada da terra como marco "civilizatório" se, na sua essência, provoca a barbárie? "Civilizatório" teria, neste caso, única e exclusivamente, o sentido de incluir a nova concepção de terra como parte dos interesses do capital.

Neste sentido concordamos com Mészáros (2003, p. 21) quando diz que não há como aceitar a argumentação do capital da necessidade de desenvolvimento (a tudo custo) no sentido de atender as crescentes necessidades humanas: "seria suicídio [...]". Há que se perguntar, neste contexto: atender as necessidades de quem? Dos trabalhadores ou do capital?

O discurso ideológico da classe dominante busca esconder as contradições produzidas pelo capital e, de forma muito perspicaz, argumenta que as mazelas justificamse ("paga-se o preço"), afinal, "todos", de alguma forma, se beneficiam do projeto e outros tantos poderão se beneficiar ("ainda há muita fome no mundo"), por isso é preciso avançar, ocupar, destruir... Mas, o pior de tudo é que esse processo todo vem legitimado pelo escuso/mal explicado conceito de sustentabilidade ${ }^{11}$. Como falarmos em desenvolvimento sustentável se, desse processo, uma multidão de trabalhadores não participam dos frutos do crescimento econômico, da produtividade, da qualidade de vida (consequência da degradação do meio ambiente)? Se entre estes, um sem-número, sequer tem acesso às condições mínimas quanto à alimentação, à moradia, à educação, ao laser; a um pedaço de terra para plantar; trabalho; renda?

Para Shiva (2003), o atual projeto do capital dá sinais evidentes do fracasso, na medida em que - e aqui está claro o papel da terra - produzir mais alimento implica em "mais fome" (p. 10). Para a autora, este projeto se apresenta como "insustentável", e o "antidesenvolvimento" (Ibid.), também é uma marca deste modelo. Chama a atenção para o fato de que essas características estão diretamente ligadas à ideologia dominante, qual seja, à monocultura das mentes. Estas monoculturas, afirma:

[...] trazem em seu bojo a convicção absoluta de que este paradigma é a solução para os problemas de todos os lugares do planeta, independentemente de localização geográfica, ecossistemas, clima, populações instaladas com organizações sociais e políticas próprias e com tradições milenares de cultivo da terra, com cuidado da biodiversidade que inclui respeito aos ciclos da vida (SHIVA, 2003, p. 10).

As monoculturas, conclui a autora, "cristalizam-se em ideologias e valores. Estes, por sua vez, orientam e justificam as políticas, as estratégias, as técnicas e os métodos utilizados para o antidesenvolvimento agrícola [...]" (Ibid. p. 11).

Portanto, há algo de errado nessa lógica, qual seja: a garantia de um direito individual justificar-se em detrimento dos direitos dos outros. Este direito, monocultor, porque individual, egoísta, justifica-se, a considerar a ameaça à diversidade? Esta questão procede na medida em que, ao se colocar a diversidade como não possibilidade, exclui-se as alternativas. Para os que trabalham a terra significa o fim dos sonhos da possibilidade da 
terra, da pequena propriedade, da reforma agrária como possibilidade, a terra como um espaço voltado à produção da vida.

Assim como os quechuas (índios) a chamam, Pacha mama (mãe), a terra tem sua importância maior na medida em que traz, na sua essência, o sentido de vida. Vida tem o sentido/significado do viver humano, sua referência, sua história, sua utopia e seu sonho.

\section{O Legal e o justo: interesses de poucos versus interesse coletivo}

[...], parece-nos possível afirmar que o acesso à terra tem significado a conquista de uma autonomia por parte das famílias beneficiadas, rebatendo diretamente na promoção da cidadania e na diminuição das injustiças sociais, [...] (LEIE E ÁVILA, 2007, p. 135).

Aos nos debruçarmos com mais cuidado sobre a atual legislação vamos perceber que esta possibilita que se façam concessões ao que está escrito. Em outras palavras, há a possibilidade de se fazer diferentes leituras e/ou interpretações sobre uma determinada lei. Sempre há algo que se possa acrescentar ou ser retirado: uma vírgula, um ponto, um adjetivo, etc. Em outros termos, permite que se façam leituras de acordo com os interesses de quem dela busca, de alguma forma, se beneficiar, tirar proveito, ter algum tipo de benefício. Isso mostra que tanto no processo de construção quanto na sua aprovação, há interesses que não, necessariamente, vem ao encontro dos interesses comum da população, mas aos interesses de uma determinada classe. Portanto, diz-se que o legal é, necessariamente, justo.

A nossa Carta Magna, ao tratar da finalidade, dos objetivos e dos fundamentos do Estado, diz que a esse compete, além da proteção aos direitos individuais, a erradicação das desigualdades sociais e da pobreza (Dos princípios fundamentais, art. $1^{\circ} \mathrm{CF}$ ). Quem a lê (em parte e/ou no todo) tem a impressão de que paira sobre os povos a mais completa felicidade, fruto da harmonia estabelecida pelas leis que, na letra da lei, resulta do poder que "emana do povo" (art. $1^{\circ}$ parágrafo único). Cria-se a sensação de que não há classes sociais, antagonismos, conflitos. O que não é verdade, pois nossa sociedade é extremamente desigual, onde as diferentes classes, com interesses antagônicos, disputam a hegemonia do poder.

A lei, como sabemos, é elaborada com uma finalidade. Está aí para servir interesses de classe que, de alguma forma ou de outra, se beneficia dela. Como afirma Marés:

As mudanças que aparecem nas normas jurídicas são sinais da vontade social e solidificam os anseios da sociedade de rompimentos, melhoras e aperfeiçoamentos. As novas leis podem ser o argumento para o povo convencer os recalcitrantes sempre empoleirados no poder (MARÉS, 2003, p. 14).

É preciso ressaltar um fato importante na atual legislação, qual seja, ela avança no sentido de questionar velhos paradigmas, comumente sustentáculos de discursos em favor de interesses de grupos e/ou de pessoas. Direitos coletivos, como os da vida, por exemplo, vem questionar velhos paradigmas que, sob o argumento da produtividade apenas, já não servem mais, como é o conceito de produtividade. Cabe caminharmos sob o entendimento de que o que se faz e se produz no campo garanta a paz no campo e o fim da fome de um sem-número de pessoas que ali vivem e trabalham. 
Se ontem ouvíamos falar em direito sagrado e inquestionável da propriedade da terra, hoje, esse direito, conforme vem sendo exercido, passou a ser questionável. Foram criados alguns pré-requisitos para que a propriedade seja, de fato, assegurada: "a lei garantirá tratamento especial à propriedade produtiva e fixará normas para o cumprimento dos requisitos relativos a sua função social" (art. 185, parágrafo único, $\mathrm{CF} / 88$ ).

Ainda é bastante comum a compreensão de que produtividade está ligada apenas à ideia de produção, pura e simplesmente, independentemente da forma e do modo como essa produção se dá. Basta que se produza alguma coisa e está garantido a prerrogativa de que a propriedade seja produtiva. Não é assim. Avançou-se bastante nesse sentido e, hoje, o conceito de produtividade tem uma estreita relação com a função social ${ }^{12}$. Isto é, quando a propriedade atender sua função social, ela, aí sim, poderá ser considerada produtiva e, consequentemente, "insuscetível de desapropriação para reforma agrária" (art. $185, \mathrm{CF} / 88)$.

A terra passa a cumprir sua função social quando, ao mesmo tempo, cumprir determinados requisitos (art. $186 \mathrm{CF} / 88$ ):

I- aproveitamento racional e adequado;

II- utilização adequada dos recursos naturais disponíveis e preservação do meio ambiente;

III- observância das disposições que regulam as relações de trabalho;

IV- exploração que favoreça o bem-estar dos proprietários e dos trabalhadores.

Percebe que aqui o novo paradigma sob o qual pauta-se o direito à propriedade individual da terra, qual seja: a terra para além dos interesses individuais, do direito de têla e usá-la, deve atender os interesses sociais. Este novo paradigma põem um certo freio a este direito que, agora, requer do/s proprietário/s elementos outros que vão além da simples denominação proprietário/dono.

Na metade do século vinte, quando ainda não estava de toda assentada a produtividade como elemento a compor o direito de propriedade da terra o mundo assistia a necessidade de preservar o meio ambiente, de manter a biodiversidade, a vida das espécies, inclusive daquelas a quem o homem chamava de nocivas (MARÉS, 2003, p. 14).

Agora percebe-se, mais nitidamente, a ideia de que ter algo, individualmente, como é o caso da terra (uso e apropriação), tem uma relação estreita com o coletivo. Não se nega o direito à propriedade da terra (este é assegurado pela legislação), mas, implica que este não seja exercido em detrimento dos direitos de um coletivo maior ${ }^{13}$.

Quantas e quantas vezes ouve-se falar que terra é sinônimo de vida. Quantos se beneficiaram e continuam a se beneficiar dela. Não há como nos separarmos dela. Não há como afirmar, em sã consciência que, de alguma ou outra forma, não estamos nos beneficiando dela. Independentemente se somos ou não donos/proprietários, se vivemos no campo ou na cidade, se plantamos ou não, se colhemos ou não: há alguém trabalhando a terra (campo), lançando as sementes, cultivando, colhendo e fazendo chegar até nós os frutos dessa atividade.

Como nossa sociedade está dividida em classes sociais, os frutos que a terra produz não chega a todos. Ou seja, há uma multidão de pessoas que não tem acesso a essa produção por falta de condições (não poder comprar). As classes pobres ficam com pouco (ou nada) do que a terra produz. Os poucos proprietários, amparados por lei, com seu 
direito quase sagrado e inviolável sobre ela, - na burla da lei - fazem dela o que lhes apraz, inclusive o direito de não produzir, de deixá-la ociosa. Esse direito tira o direito de muitos terem um pouco, o necessário.

Há, na forma da lei, uma clara opção pelo que esta lhe garante: o direito de ter, de ser dono, ser proprietário, usufruir da forma que melhor lhe convier. Mas, na prática, não significa uma opção pela vida. Não só a humana, mas de toda forma de vida (fauna e flora). Passa-se ao largo do que diz a Constituição quanto à função humana (respeito à vida) e social (distribuição equitativa da riqueza ou bem estar social rural). Aliás, além destas, temos a função econômica - incremento racional da produção e ecológica conservação dos recursos naturais renováveis (ZIBETTI, 2005).

$\mathrm{O}$ acesso à terra e os bens que dela advém, basicamente os alimentos e a água, passam a constituir-se como um dos direitos básicos das pessoas. O não acesso constituise, portanto, em um impeditivo para a promoção do desenvolvimento e da justiça. A fome é a negação do acesso aos bens produzidos pela terra ${ }^{14}$. A negação da própria vida.

As grandes propriedades improdutivas, portanto, sujeitas à desapropriação (art. 184, CF/1988), estão na mão de uns poucos, a classe dominante (burguesia rural e urbana). O projeto do capital, aliado aos interesses das agências internacionais, transformou a terra de trabalho em terra de negócio. A mercantilização da terra, característica do projeto neoliberal para o campo, não leva em conta a função social da terra. Esta não passa de uma mera mercadoria. E a lei, contida na Constituição, ao que nos parece, como diz Lassalle (apud MARÉS, 2003, p. 121), "é uma folha de papel sujeita ao uso das classes dominantes". Mais do que isso, temos que ter claro que o cumprimento da lei dá-se numa arena de disputa de forças reais de poder.

Como estamos falando da propriedade da terra, importa dizer que, neste contexto,

[...] os camponeses estão aí, disputam o espaço público, politizam o cotidiano e buscam aprender as regras do jogo da política, mudar de posição social e buscar caminhos para romper a subalternidade (MEDEIROS apud LEITE e ÁVILA, 2007, p. 11).

Em outros termos, estamos falando do sonho da terra, da terra como possibilidades, como espaço de vida, de vivência, convivências; mas, sobretudo, de um espaço que nutre utopias e que alimenta resistências, recusas, e que, mais do que uma mercadoria, representa a vida. Portanto, a terra - tê-la - que dá aos filhos vida, alimentos, proteção -, tem sua importância para além do que a lei determina. A lei é um marco legal, apenas, nem sempre é o mais justo. Está aqui o sentido da luta dos movimentos sociais do campo: a luta pela terra. Terra de trabalho. Terra que lhes assegure uma vida digna. Mesmo que esta busca implique avançar para além dos marcos, das cercas, dos limites que são impostos pela lei.

Como nos lembra Bezerra Neto (1999, p. 37), “geralmente são os oprimidos os portadores de novas visões, aqueles que, embora derrotados, nunca desistem, resistem firmemente e sempre de novo retomam a luta". Para Boff (apud BEZERRA NETO, 1999, p. 37), "O que os move são os sonhos de uma realidade nova. Por isso, desfatalizam a história, não reconhecem como ditado da história a situação injusta imposta e mantida pelas forças opressoras".

Importa, por fim, ressaltar que os trabalhadores do campo/camponeses, há bastante tempo, entenderam que "[...] não é no plano espiritual que se situa a solução para a sofrida condição, [...]” (RODRIGUES, 1991, p. 86), mas na luta concreta contra a classe 
que os oprime, a burguesia rural, sob a orientação das políticas neoliberais para o campo o agronegócio, este modelo extremamente excludente, opressor e classista.

\section{Considerações finais}

O direito de propriedade não é outra coisa senão concentrar a produção em uma parcela determinada de terra e, na atualidade, transformar essa concentração em proveito de uma única ou mais pessoas. [...] essa construção histórica criou um discurso de que propriedade da terra pode ser imperfeita, mas sagrada (FELICIANO, 2015, p. 139-40).

Outra interpretação, outro entendimento e práticas sobre o uso e posse da terra, diferentemente do que vem ocorrendo com a propriedade privada da terra, continua a gerar controvérsias. O que sempre foi visto como direito absoluto e sagrado, passa a gerar questionamentos, discussões, polêmicas, tensões, dentro do campo do direito: o direito de uns poucos está acima do direito de muitos?

Para alguns, a ciência e a tecnologia aplicadas à produção, e a consequente mudança nas estruturas produtiva no campo, prescindem de novas mudanças no campo, como, por exemplo, àquelas voltadas a atender as exigências quanto à função social da terra. Para outros, é imprescindível que se leve em consideração estes aspectos, uma vez que a função social da propriedade possibilita que haja justiça no campo, desenvolvimento sustentável, onde todos possam se beneficiar dos avanços da modernização trazida pela ciência e pela tecnologia.

Tratar da função social da terra, hoje, é muito importante. Não há nada que confirme (como alguns querem fazer crer) o fim dos povos do campo. Pelo contrário, o que há é o fortalecimento das organizações dos trabalhadores que lidam com a terra. Tome-se como exemplo, a Via Campesina ${ }^{15}$.

As muitas questões colocadas ao longo do texto, quanto à função social da terra, tem, na sua essência, a defesa do uso racional da terra, voltada aos interesses sociais, ao coletivo. A terra, e sua fincão social, como forma de redução da pobreza, mas, sobretudo, como instrumento de justiça social no campo (LEITE e ÁVILA, 2007). Pacha mama quer significar terra que produz e reproduz a vida. Os povos originários já tinham essa concepção. A sua (quase) total destruição justifica nossa preocupação para com o futuro do planeta, o futuro das mais diferentes formas de vida, inclusiva a dos homens e mulheres. Quer a lei garanta ou não esta possibilidade, existem outras tantas formas (armas definitivas) de garantir/preservar a vida, uma é libertar-nos, se necessário, do jugo intolerável, congelado em lei (NATHAN e NORDEN apud MÉSZÁROS, 2003, p. 85).

\section{Referências}

BEZERRA NETO, Luiz. Sem- Terra aprende e ensina: estudo sobre as práticas educativas do movimento dos trabalhadores rurais. Campinas, SP: Autores Associados, 1999.

BRASIL. Constituição da República Federativa do Brasil. Brasília: Senado Federal, 2008.

FELICIANO. Carlos A. Estado, Apropriação e Concentração de Terra e Poder: Da Propriedade Como Direito Natural ao Questionamento da Função Social da terra. In: 
MIDITIERO JUNIOR, Marco A.; GARCIA, Maria F.; VIANA, Pedro C. Guedes (orgs.). A Questão Agrária no Século XXI: escolas, dinâmicas e conflitos Territoriais. São Paulo: Outras Expressões, 2015.

LEITE, Sérgio P.; ÁVILA, R. Vieira de. Um futuro para o campo: reforma agrária e desenvolvimento social. Rio de Janeiro: Vieira \& Lent, 2007.

MARÉS, Carlos Frederico. A Função Social da Terra. Porto Alegre: PENA Composição e Arte, 2003.

MARX, Karl; ENGELS, Friedrich. Manifesto Comunista. São Paulo: Boitempo Editorial, 2002.

MÉSZÁROS, István. O século XXI socialismo ou barbárie? São Paulo: Boitempo Editorial, 2003.

OLIVEIRA, Jelson. Teologia Simbólica da Terra. Disponível em: www. cpt.org.br. Acesso em: setembro de 2010.

PERIPOLLI, Odimar J. Expansão do Capitalismo na Amazônia Norte Mato-grossense: a mercantilização da terra e da escola. (Tese de Doutorado). PPGEDU/UFRGS. Porto Alegre, 2009.

RODRIGUES, Marlene. Cartilhas da dominação: a ideologia das primeiras letras nos campos do Brasil. Curitiba: Ed. da UFPR, 1991.

SHIVA, Vandana. A Monocultura da Mente: perspectivas da Biodiversidade e da Biotecnologia. São Paulo: Gaia, 2003.

ZIBETTI, DARCY, W. Teoria tridimensional da função social da terra no espaço rural. Curitiba: Juruá, 2005.

ZOIA, Alceu., PERIPOLLI, Odimar J. . Uma escola para os sujeitos do campo: a questão das especificidades do ensino. Revista Educação, Cultura e Sociedade, v. 5, p. 33-44, n. 2015.

\section{Notas}

\footnotetext{
${ }^{1}$ Professor Doutor vinculado à Faculdade de Educação e Linguagem - FAEL, Sinop/MT e ao PPGEdu UNEMAT, Cáceres /MT.

${ }^{2}$ Professor Doutor vinculado à Faculdade de Educação e Linguagem - FAEL, Sinop/MT e ao PPGEdu UNEMAT, Cáceres /MT.

${ }^{3}$ Pseudônimo de Hamilton Pereira da Silva, militante da Ação Libertadora Nacional (ALN), foi preso em 10 de junho de 1972, quando tinha 24 anos, em Anápolis, Goiás. Era acusado de subversão e de atentar contra a segurança nacional. Condenado inicialmente a 12 anos de reclusão - incluindo 1 ano de "medida de segurança detentiva" -, sua pena foi fixada, após recurso, em cinco anos. Ele somente foi solto em 10 de março de 1977, após cumpri-la integralmente.

4 "A vida grupal nômade lhes conferia uma espécie de comunismo primitivo, no qual tudo era de todos" (ZIBETTI, 2005, p. 55). "[...]". "O sentimento de propriedade privada de algum bem se reservava, quanto muito, às parcas vestimentas protetoras do frio".

${ }^{5}$ Pacha Mama, do quíchua Pacha ("universo, mundo, tempo, lugar") e de Mama ("mãe"): "Mãe terra", é a deidade máxima dos Andes peruanos, bolivianos, do noroeste argentino e do extremo norte do Chile. É representada por uma figura huamana, uma mulher levando ao colo uma criança (MARÉS, 2003, P. 11).

${ }^{6}$ Comunismo primitivo: é um tipo de organização social baseado na propriedade comunal da terra, geralmente por motivos religiosos. É característico de algumas formações sociais antigas. Nenhum país hoje pode ser considerado como organizado desta forma, mas talvez algumas tribos. Todos os países do mundo (a exceção dos comunistas, em tese) se organizam num modo de produção capitalista.
} 
${ }^{7}$ Para o autor, esta forma de conceber a propriedade decorre dos códigos napoleônicos (século XIX), especificamente o de 1804, onde se refletiram mais intensamente "os anseios da classe média emergente coma Revolução - a classe proprietária" (2005, p. 87).

8 "Em média, a cada seis dias, uma pessoa é assassinada no campo brasileiro" (FELICIANO, 2015, p. 125). Segundo o autor, esta média resulta do cálculo a partir do número de assassinatos no período de 1985 a 2013, registrados pela CPT (Comissão Pastora da Terra).

${ }^{9}$ Ver Peripolli (2009) e Zoia e Peripolli (2015), dentre outras publicações.

${ }^{10} \mathrm{O}$ significado da expressão favelização do campo reporta-nos à forma como muitas famílias camponesas vivem hoje, sobretudo, em projetos de reforma agrária, cuja condição - baixa escolaridade, renda mínima se assemelha à vida de muitos que vivem em favelas nas grandes cidades: marcada pela falta de políticas públicas que lhes possibilidade uma vida digna.

${ }^{11} \mathrm{O}$ conceito de sustentabilidade, comumente usado, é o que define ações e atividades humanas que visam suprir as necessidades atuais dos seres humanos, sem comprometer o futuro das próximas gerações.

${ }_{12}$ Segundo Zibetti $(2005$, p. 53), é provável que tenha havido "influência do pensamento católico, consubstanciado principalmente nas reiteradas Encíclicas papais, que essa idéia da função social da propriedade engloba o interesse social, dimensionado em tempo, lugar e oportunidade".

${ }^{13} \mathrm{O}$ decreto de desapropriação por interesse social para fins der reforma agrária, ressalta Zibetti (2005, p. 53), "materializa a supremacia do interesse social sobre o individual, pessoal e particular, mediante pagamento indenizatório".

${ }^{14}$ Segundo dados da FAO (apud Leite e Ávila (2007, p. 29), 852 milhões de pessoas passam fome no mundo. Os números da fome mostram que há uma relação muito estreita/direta com concentração fundiária.

${ }^{15}$ A Via Campesina é um movimento internacional que coordena organizações camponesas de pequenos e médios agricultores, trabalhadores agrícolas, mulheres rurais e comunidades indígenas da Ásia, África, América e Europa. Trata-se de um movimento autônomo, pluralista, mas com ligações políticas e econômicas. Está formada por organizações nacionais e regionais cuja autonomia é cuidadosamente respeitada. Está organizada em 8 regiões: Europa do Leste, Europa do Oeste, Nordeste e Sudeste da Ásia, Sul da Ásia, América do Norte, Caribe, América Central, América do Sul e na África.

Recebido: março/16 Aprovado: dezembro/16 